REVISTA DE DERECHO UNED, NÚM. 28, 2021

\title{
EL PRINCIPIO DE CAPACIDAD ECONÓMICA EN LOS RENDIMIENTOS DE ACTIVIDADES ECONÓMICAS DETERMINADOS CON EL MÉTODO DE ESTIMACIÓN DIRECTA EN EL IMPUESTO SOBRE LA RENTA DE LAS PERSONAS FÍSICAS
}

THE PRINCIPLE OF TAXPAYING CAPACITY IN THE INCOME ECONOMIC ACTIVITIES DETERMINED BY THE METHOD OF DIRECT ESTIMATION IN PERSONAL INCOME TAX

\section{VERÓNICA ARribas GARCIA}

Doctorando. Programa Doctorado de Derecho y Economía de Ceindo Universidad San Pablo CEU-CEU Universities

Facultad de Derecho

Sumario: I. Introducción. II. Fundamento de la capacidad económica. III. Significado y contenido del principio de capacidad económica. IV. Vertientes del principio de capacidad económica. $V$. Tratamiento doctrinal del principio de capacidad económica. VI. Conclusiones.

Resumen: Este trabajo plantea un análisis sobre el cumplimiento del principio de capacidad económica contemplado en el artículo 31.1 de la Constitución Española en el ámbito de los rendimientos netos de actividades económicas determinados con el método de estimación directa en el Impuesto sobre la Renta de las Personas Físicas. Para ello, se ha efectuado un estudio del principio de capacidad económica tratando su fundamento, significado y contenido, considerando la jurisprudencia y la doctrina existente hasta el momento. La finalidad es demostrar las posibles lesiones que la normativa vigente y las resoluciones administrativas y judiciales pueden 
estar infringiendo al derecho de contribuir con arreglo a su capacidad económica de los contribuyentes de actividades económicas, cuyo rendimiento neto se determina con el método de estimación directa, en relación a la estimación de la deducibilidad de gastos de suministros y derivados de la utilización de uso de vehículo turismo.

Palabras Clave: principio de capacidad económica, Impuesto sobre la Renta de las Personas Físicas, Actividades Económicas, método de estimación directa, gastos deducibles.

Summary: This work proposes an analysis on the fulfilment of the principle of ability to pay referred to in article 31.1 of the Spanish Constitution in the field of net income from economic activities determined by the method of direct estimation in the Personal Income Tax. To this end, a study of the principle of ability to pay has been carried out by addressing its merits, meaning and content, taking into account the case-law and doctrine that exists so far. The purpose is to demonstrate the possible injuries that existing legislation and administrative and judicial decisions may be infringing the right to contribute according to their economic capacity that taxpayers of economic activities whose net performance is determined by the method of direct estimation as to the estimate of the deductibility of supply costs and arising from the use of tourist vehicle use.

Keywords: principle of ability to pay, Personal Income Tax, Economic Activities, method of direct estimation, deductible expenses.

Recepción original:20-05-2021

Aceptación original:14-09-2021

\section{INTRODUCCIÓN}

El principio de capacidad económica se recoge en el artículo 31.1 de la CE que establece que "todos contribuirán al sostenimiento del gasto público de acuerdo con su capacidad económica mediante un sistema tributario justo, inspirado en los principios de igualdad y progresividad, que en ningún caso tendrá alcance confiscatorio".

Se trata de un principio impositivo y, como tal, conforma el sistema tributario en un momento determinado. Así lo entiende FUENTES QUINTANA ${ }^{1}$, al indicar que la construcción o validez del sistema tributario es siempre hipotética: si el sistema tributario

1 Fuentes Quintana, E.: Prólogo del libro de Fritz Neumark, Principios de la Imposición. Instituto de Estudios Fiscales. 2a Edición en español. Madrid. 1994, 
pretende lograr esta o aquella finalidad, entonces debe cumplir con éste o aquel principio. A tenor de lo indicado por FUENTES QUINTANA, parece que nuestro ordenamiento jurídico tributario está basado en el principio de contribución con las cargas públicas de acuerdo con la capacidad económica. Así, el artículo 3.1 de la L.G.T. indica que "la ordenación del sistema tributario se basa en la capacidad económica de las personas obligadas a satisfacer los tributos y en los principios de justicia, generalidad, igualdad, progresividad, equitativa distribución de la carga tributaria y no confiscatoriedad".

Como se puede observar, tanto la CE como la LGT recogen el principio de capacidad económica, pero no se ofrece en ninguno de los cuerpos legislativos el concepto, contenido y alcance del mismo. Esto supone que el desarrollo del principio de capacidad económica es de orden doctrinal y jurisprudencial en nuestro país y, en el último caso, veremos de conformidad con lo expuesto en este capítulo que, tampoco da un criterio uniforme respecto al concepto, contenido y desarrollo del principio indicado. Lo que nos lleva, fundamentalmente, a tener en cuenta los estudios doctrinales al respecto.

En relación con lo expuesto en el párrafo anterior, TIPKE ${ }^{2}$ indica que no es suficiente que los Estados de Derecho persigan la seguridad jurídica, sino que también deben elaborar un derecho material justo y, en este sentido, tal y como indica HERRERA MOLINA ${ }^{3}$, la capacidad económica supone un criterio racional de diferenciación puesto que los impuestos deben ser graduados en función de la riqueza o la fuerza económica de los contribuyentes.

$\mathrm{Y}$, teniendo en cuenta que, el ámbito de nuestro estudio, se refiere a la posible vulneración, derivada de algunos preceptos de la Ley y la aplicación en determinados supuestos por los tribunales y la Administración, que los contribuyentes en actividades económicas en método de estimación directa pueden estar sufriendo de su derecho de contribuir conforme a la capacidad económica por resoluciones de los Tribunales y de la propia legislación, consideramos esencial hacer

p. XXIII. Ob. cit. Calderón Corredor, Z.: Principios impositivos de justicia y eficiencia: fundamentos, conflicto y proyección. Madrid, 2017, págs.38-39

${ }_{2}$ Tipke,K.: Prólogo del Libro "Capacidad económica y sistema fiscal. Análisis del ordenamiento español a la luz del Derecho alemán" de Herrera Molina, P.M., Editorial Marcial Pons. Madrid, 1998, pág.13

3 Herrera Molina, P. M.: "Capacidad económica y sistema fiscal. Análisis del ordenamiento español a la luz del Derecho alemán”, Editorial Marcial Pons. Madrid, 1998, pág. 23 
en el presente capítulo un pequeño estudio del principio indicado y realizar nuestra humilde contribución a la doctrina existente.

\section{FUNDAMENTO DE LA CAPACIDAD ECONÓMICA}

HERRERA MOLINA ${ }^{4}$ indica que el fin recaudatorio exige gravar las fuentes de riqueza. Esta afirmación no ofrece ninguna justificación de los impuestos y, por tanto, no suministra medida de su distribución. El autor considera que la evolución de la jurisprudencia y la doctrina muestra la necesidad de elaborar un derecho fundamental a contribuir con arreglo a la capacidad económica y, para ello, es preciso analizar el fundamento y posición del principio de capacidad económica en el orden constitucional.

El artículo 10.1 de la CE indica que "la dignidad de la persona, los derechos inviolables que le son inherentes, el libre desarrollo de la personalidad, el respeto a la ley y a los derechos de los demás son fundamento del orden político y de la paz social", lo que supone que los derechos fundamentales tienen su fundamento último en la dignidad de la persona.

Si bien, hay que tener en cuenta que los derechos llevan parejos unos deberes. Así, HERRERA MOLINA ${ }^{5}$ apunta que, por un lado, el derecho a contribuir conforme a la capacidad económica está unido al deber de contribuir y, en este aspecto, el principio indicado garantiza la igualdad de trato en el sostenimiento de cargas públicas y, por otro lado, la capacidad económica supone la medida del deber de contribuir, medida que es un deber de solidaridad hacia los demás hombres.

HERRERA MOLINA pone así de relevancia la conexión del principio de capacidad económica con el principio de igualdad y la solidaridad.

En relación con el principio de igualdad, HERERRA MOLINA ${ }^{6}$ trae a colación la STC 76/1990, de 26 de abril de 1990, en F.J. $9^{\circ}$, e indica que el TC fija doctrina en el sentido:

- No toda desigualdad de trato en la Ley supone una infracción del artículo $14 \mathrm{CE}$, sino que dicha infracción la produce sólo

4 Herrera Molina, P. M.: "Capacidad económica y sistema fiscal. Análisis del ordenamiento español a la luz del Derecho alemán”, Editorial Marcial Pons. Madrid, 1998, pág. 81

5 Ob. cit., pág. 82

6 Ob. cit., págs. $84-92$ 
aquella desigualdad que introduce una diferencia entre situaciones que pueden considerarse iguales y que carece de una justificación objetiva y razonable.

- El principio de igualdad exige que a iguales supuestos de hecho se apliquen iguales consecuencias jurídicas.

- El principio de igualdad no prohíbe al legislador cualquier desigualdad de trato, sino sólo aquellas desigualdades injustificadas.

- Es indisponible que las consecuencias jurídicas que resultan de tal distinción sean adecuadas y desproporcionadas.

En cuanto al principio de capacidad económica como criterio de reparto impositivo, HERRERA MOLINA indica que el interés general puede definirse como el conjunto de condiciones y de bienes sociales necesarios para el pleno y libre desarrollo de la personalidad.

La contribución al interés general representa una exigencia del carácter social de la naturaleza humana que está directamente relacionado con el principio de solidaridad. La persona tiene una responsabilidad frente al bien común a la que debe contribuir en función de su capacidad.

\section{SIGNIFICADO Y CONTENIDO DEL PRINCIPIO DE CAPACIDAD ECONÓMICA}

HERRERA MOLINA ${ }^{7}$ indica que en Alemania no se reconoce el principio de capacidad económica dentro de la Ley Fundamental de Bonn. Sin embargo, el Tribunal Constitucional alemán lo ha considerado como una manifestación del derecho a la igualdad y como un valor independiente de la interdicción de la arbitrariedad, por entender, bien que es un auténtico criterio de reparto de cargas o por entender que no sólo se encuentra en el derecho a la igualdad sino también en las cláusulas del Estado de Derecho y del Estado Social; y en Italia -el principio de capacitá contributiva recogido en la Constitución de 1947, artículo 53 (que sirvió de base a nuestro principio de capacidad económica)—, se interpreta la capacidad económica como principio (y así lo entiende la Corte Constitucional) y

7 Herrera Molina, P. M.: “Capacidad económica y sistema fiscal. Análisis del ordenamiento español a la luz del Derecho alemán”, Editorial Marcial Pons. Madrid, 1998, págs. 29 y 43 a 47. 
como criterio de reparto de la carga tributaria (cuya realización está en manos del legislador).

De conformidad con la STC 27/1981, F.J. 4 " "Capacidad económica a efectos de contribuir a los gastos públicos, tanto significa como la incorporación de una exigencia lógica que obliga a buscar la riqueza alli donde la riqueza se encuentra." Y así lo vuelve a reiterar en su STC 37/1987, de 26 de marzo, analizando su relación con fines extrafiscales del tributo, en cuyo F.J. $13^{\circ}$, indica que "es constitucionalmente admisible que el Estado, y las Comunidades Autónomas en el ámbito de sus competencias, establezcan impuestos que, sin desconocer o contradecir el principio de capacidad económica o de pago, respondan principalmente a criterios económicos o sociales orientados al cumplimiento de fines o a la satisfacción de intereses públicos que la Constitución preconiza o garantiza. Basta que dicha capacidad económica exista, como riqueza o renta real o potencial en la generalidad de los supuestos contemplados por el legislador al crear el impuesto, para que aquel principio constitucional quede a salvo". En esta sentencia, el TC incluye el concepto de "renta potencial" que analizaremos en el epígrafe IV de este estudio.

En STC 209/1988, en el F.J. $8^{\circ}$, se indica que el legislador ha de ordenar la tributación sobre la renta en atención a la capacidad económica que muestren los sujetos pasivos del impuesto, al ser la capacidad, en este ámbito, medida de igualdad... En este sentido se expresa también PÉREZ DE AYALA ${ }^{8}$ al indicar que para que el Impuesto sea realmente justo y no se produzcan disfunciones, será necesario que la realidad gravada esté referida y ponga de manifiesto una capacidad económica del sujeto, que es el objeto que el legislador toma como referencia para establecer sobre él el correspondiente impuesto porque refleja, efectivamente, una verdadera capacidad de pago del individuo.

Según el Prof. SAINZ DE BUJANDA9 ${ }^{9}$ la capacidad económica se identifica con la capacidad contributiva en nuestro sistema. El profesor indica que la doctrina distingue entre capacidad contributiva absoluta, - entendida como la aptitud abstracta para concurrir a las cargas públicas y la que se tiene en cuenta en el momento de delimitar los presupuestos de hecho-; y la capacidad contributiva relativa, — entendida como el criterio que debe orientar la determinación de

\footnotetext{
8 Pérez de Ayala Becerril, M., "Fundamentos de Derecho impositivo estatal", Edersa. Madrid, 1995, pág.39.

9 Sainz de Bujanda, F: "Lecciones de Derecho Financiero". Sección Publicaciones UCM. Facultad de Derecho. Madrid 1982, págs. 107-110.
} 
la carga tributaria concreta, que es la que se tiene en cuenta para la fijación de elementos de cuantificación de la deuda tributaria-.

SAINZ DE BUJANDA considera complicado delimitar los presupuestos objetivos de los tributos. Enumera, el autor, diferentes hechos o índices que pueden poner de manifiesto capacidad contributiva (así la percepción de renta, la posesión de bienes, la circulación, etc.). No obstante, SAINZ DE BUJANDA considera que ninguno de ellos puede tomarse como manifestaciones de capacidad económica abstracta para la imposición de tributos.

En cuanto a la capacidad contributiva relativa (reparto de la carga tributaria), SAINZ DE BUJANDA, indica que el reparto de dicha carga exige la determinación cuantitativa concreta de la prestación tributaria de cada individuo. En este sentido, para el profesor, no basta con saber que se ha de contribuir al sostenimiento de las cargas públicas; más bien es necesario saber la capacidad económica de cada sujeto. Y ello, porque la capacidad contributiva relativa se traduce en la determinación de la cuantía de la deuda tributaria individual. El autor sostiene que para determinar la deuda tributaria individual es necesaria la combinación de los siguientes criterios esenciales: la estructura, proporcional o progresiva, de los tipos de gravamen, y el carácter, objetivo o subjetivo, del tributo.

Para MASBERNAT MUÑOZ ${ }^{10}$, la capacidad económica hace relación con la potencialidad económica vinculada a la titularidad y disponibilidad de la riqueza. Este autor diferencia, siguiendo a SÁINZ DE BUJANDA ${ }^{11}$ y CASADO OLLERO ${ }^{12}$, entre capacidad económica absoluta, —capacidad abstracta para concurrir al sostenimiento de las cargas públicas- (lo que CASADO OLLERO entiende como criterio de contribuir al sostenimiento del gasto público), y capacidad económica relativa - la capacidad económica que orienta y modula la carga tributaria que un contribuyente debe soportar- (lo que CASADO OLLERO considera como fuente de la imposición). En el mismo sentido de considerar que la capacidad contributiva es una

10 Masbernat Muñoz, P.: "El principio de capacidad económica como principio jurídico material de la tributación: su elaboración doctrinal y jurisprudencial en España". Revista Ius et Praxis. Año 16, No 1. 2020, págs.303-332.

11 Sainz de Bujanda, F: "Lecciones de Derecho Financiero". Sección Publicaciones UCM. Facultad de Derecho. Madrid 1982, págs. 107-110

12 Casado Ollero, G.: "El principio de capacidad y el control constitucional de la imposición indirecta (II). El contenido constitucional de la capacidad económica". Revista Española del Derecho Financiero No 34. 1982, pág.185. 
expresión de la potencia económica global del contribuyente, se manifiesta MOSCHETTI ${ }^{13}$.

Para DE VICENTE DE LA CASA ${ }^{14}$ la capacidad económica es el punto de partida conforme al cual deber realizarse nuestra contribución al sostenimiento de las cargas públicas.

De todo ello se entiende que el principio de capacidad económica hace referencia a la titularidad de riqueza, esto es, de medios económicos para poder hacer efectivo el pago de un tributo. Parece, pues, referida a la capacidad económica individual globalmente considerada, tal y como indica CALDERÓN CORREDOR ${ }^{15}$, que considera que la titularidad de riqueza debe valorarse conforme a los criterios de justicia aplicables al orden tributario con la finalidad de determinar si debe ser objeto de gravamen o no (no lo sería aquella que se destina por ejemplo a la satisfacción de las necesidades fundamentales o mínimo vital).

El principio de capacidad económica, como guía y límite del legislador solo permite someter al impuesto aquellos supuestos que revelen capacidad para el pago, lo cual no significa someter a tributación todas las situaciones que sean indicios de la misma. La decisión de gravar unas manifestaciones de riqueza, y no otras, debe resultar fundamentada en el principio de igualdad, es decir, en razones que justifiquen la razón de la diferencia, que eliminen todo indicio de arbitrariedad, recogiendo lo expuesto por

Para GOROSPE OVIEDO y HERRERA MOLINA ${ }^{16}$, el contenido ideal del principio de capacidad económica es la riqueza disponible de un sujeto. Esto supondría que dicho principio debería exigir el cumplimiento de los siguientes extremos:

a) El principio del neto objetivo que exige que sólo tribute la renta neta y no las sumas destinadas a obtener ingresos, de modo tal,

13 Moschetti, F.: "El principio de capacidad contributiva." Instituto de Estudios Fiscales. Ministerio de Hacienda. Madrid, 1980, págs. 73

14 Vicente de la Casa, F.: "Los principios de capacidad económica y no confiscatoriedad como límite a la concurrencia de tributos". Crónica Tributaria N ${ }^{\circ}$ 144/2012. págs. 149-175

15 Calderón Corredor, Z.: "Principios impositivos de justicia y eficiencia: fundamentos, conflicto y proyección. Un enfoque multidisciplinar". Editorial Dykinson. Colección Fiscalidad. Madrid, 2017. pág. 114.

16 Gorospe Oviedo, Juan I. y Herrera Molina, Pedro M.: "La virtualidad del principio de capacidad económica en el ordenamiento tributario español". En Albiñana, César. (Coord.) Estudios en homenaje al profesor Pérez de Ayala. Dykinson. 2007, págs.29-56 
que la carga tributaria global sea en función de la capacidad económica de cada contribuyente.

HERRERA MOLINA ${ }^{17}$ indica que el principio de tributación de los rendimientos netos es una exigencia lógica de que el gravamen recaiga sobre la riqueza disponible. Aunque el autor considera que la riqueza disponible es un principio genérico que debe concretar el legislador, sin embargo, propone algunas técnicas para su concreción:

- Deducibilidad de gastos necesarios para la obtención de ingresos

- Deducibilidad de gastos originados por la actividad empresarial

- Beneficios derivados de la contabilidad mercantil

A tenor de lo expuesto, cualquiera de las tres técnicas propuestas por HERRERA MOLINA, contemplan la posibilidad de dejar al margen del cálculo de los rendimientos netos, los ingresos destinados a los gastos necesarios para la actividad económica en método de estimación directa, con lo cual, los rendimientos netos obtenidos del cálculo indicado sí representarían de forma más realista la capacidad económica del contribuyente para contribuir a las cargas públicas. No obstante, el autor, reconoce que se puedan establecer excepciones fundadas en razones de estricta justicia, objetivos extrafiscales y razones de practicabilidad administrativa.

Lo indicado es relevante tal y como se indicará más adelante ya que, actualmente, los contribuyentes de actividades económicas, deben declarar todos los ingresos y los gastos quedando, en la mayoría de las ocasiones, la deducibilidad de gastos necesarios (como el caso de gastos de suministros derivados de la utilización de una parte de la vivienda para la actividad económica) reducida a una cuestión probatoria, lo que obliga a los contribuyentes, en muchas ocasiones a gastos extraordinarios en reclamaciones económico-administrativas y recursos contencioso-administrativos a fin de a hacer valer su derecho legítimo.

17 Herrera Molina, P. M.: “Capacidad económica y sistema fiscal. Análisis del ordenamiento español a la luz del Derecho alemán”, Editorial Marcial Pons. Madrid, 1998, pág.117 
b) El principio del neto subjetivo o de exoneración del mínimo existencial personal y familiar, que dispone que no deben tributar las cantidades necesarias para garantizar al contribuyente y a su familia una vida digna, lo que hace referencia directamente al principio del neto subjetivo o de exoneración de mínimo existencial personal y familiar.

$\mathrm{Al}$ respecto, HERRERA MOLINA ${ }^{18}$ considera que el principio de capacidad económica para contribuir a los gastos públicos comienza una vez que se ha cubierto el mínimo necesario para la existencia. Para el autor, exige un mínimo personal y familiar exento ajustado a la realidad en la que influyen factores de hecho y de derecho:

- El coste de la vida que varía en el lugar y en el tiempo

- El grado de bienestar alcanzado por la sociedad sobre el nivel de vida considerado mínimo.

- El nivel de prestaciones sociales

c) El principio de tributación de la riqueza efectiva que exige que sólo tribute la riqueza real y no rendimientos ficticios o nominales.

$\mathrm{Al}$ respecto, hay que indicar que en el Impuesto sobre la Renta de las Personas Físicas se tienen en cuenta unos mínimos personales y familiares exentos. Se entiende por mínimo personal y familiar la parte de la base liquidable que no se somete a tributación por destinarse a satisfacer las necesidades básicas personales y familiares. Para MOSCHETT ${ }^{19} \mathrm{I}$, este mínimo vital, tiene que ser suficiente, en todo caso, para asegurar a sí mismo y a su familia una existencia libre y digna.

Teniendo en cuenta lo acabado de mencionar, habría que preguntar al legislador si entiende que los mínimos individuales y personales recogidos actualmente en la LIRPF cubren suficientemente las necesidades básicas de los contribuyentes. La respuesta parece obvia, y trayendo a colación lo indicado por GOROSPE OVIEDO y HERRERA MOLINA, debería ajustarse dichos mínimos personales y familiares en base a la capacidad económica del sujeto que incluya el principio del neto subjetivo por cuanto los mínimos personales y

18 Herrera Molina, P. M.: “Capacidad económica y sistema fiscal. Análisis del ordenamiento español a la luz del Derecho alemán”, Editorial Marcial Pons. Madrid, 1998, pág.121

${ }_{19}$ Moschetti, F.: "El principio de capacidad contributiva." Instituto de Estudios Fiscales. Ministerio de Hacienda. Madrid, 1980, pág. 269 
familiares establecidos en el Impuesto indicado, son muy reducidos $\mathrm{y}$, en todo caso, alejados del momento en que vivimos; lo que lleva a cuestionar si, realmente, el mencionado impuesto, respeta el principio de capacidad económica de los contribuyentes. Sería conveniente que dicho mínimo individual y familiar fuera revisado y actualizado, puesto que no parece razonable que una persona pueda mantenerse con $5.550,00 €$ anuales y de $2.400,00 €$ a $4.500 €$ por hijo. Más aún, cuando, conforme al art. 63.1 apartado $2^{\circ}$ LIRPF, tras su reforma por el artículo 1.39 de la Ley 26/2014, de 27 de noviembre, su importe se deduce de la cuota, por lo que el descuento real es solo el 19 por 100 de esas cantidades.

A este principio de neto subjetivo en relación con el mínimo personal y familiar, en el caso de contribuyentes en actividades económicas cuyo resultado se determina por el método de estimación directa, debería tenerse en cuenta el principio de neto objetivo. Consideramos que puede ser viable la concurrencia de la aplicación de ambos principios, por cuanto, un contribuyente en actividades económicas acogidos al método de estimación directa puede declarar la renta neta (entendida por tal la diferencia entre los ingresos y los gastos necesarios para la obtención de dichos gastos), y también puede serle aplicable el principio del neto subjetivo, que se aplicaría en régimen de igualdad tributaria al resto de los obligados tributarios. MOSCHETTI ${ }^{20}$ también refiere la necesidad, al gravar los recursos, de tener en cuenta todos aquellos gastos y elementos pasivos que, aun no siendo inherentes a la producción de la renta, influyen en cualquier caso sobre la situación económica del contribuyente.

En el mismo sentido se manifiesta PÉREZ DE AYALA ${ }^{21}$ al considerar que un impuesto será confiscatorio, ya que merecerá esta calificación desde el momento en que absorba parte de los recursos necesarios para que el contribuyente mantenga su nivel de vida y su actividad productiva.

Al hilo de lo expuesto y en otro sentido, CALDERÓN CORREDOR $^{22}$ indica que el nivel de fraude existente y la proliferación de

20 Moschetti, F.: "El principio de capacidad contributiva." Instituto de Estudios Fiscales. Ministerio de Hacienda. Madrid, 1980, pág. 266

21 Pérez de Ayala, J.L.: "Las cargas públicas: principios para su distribución" en HPE, 1979, p.111. Herrera Molina P. M.: "Capacidad económica y sistema fiscal. Análisis del ordenamiento español a la luz del Derecho alemán”, Editorial Marcial Pons. Madrid, 1998, pág.131.

${ }_{22}$ Calderón Corredor, Z.: "Principios impositivos de justicia y eficiencia: fundamentos, conflicto y proyección. Un enfoque multidisciplinar". Editorial Dykinson. Colección Fiscalidad. Madrid, 2017. pág. 115. 
tratamientos tributarios preferenciales son dos cuestiones que pueden erosionar la vigencia del principio de capacidad económica, erosión a la que también contribuye, sin ningún género de dudas, las diferencias de criterios esgrimidos por Tribunales Económico-Administrativos a los que nos referiremos.

Así, en Resolución del TEAC 00/04454/2014, dictada con fecha 10 de septiembre del 2015, se indica, en su F.J. $4^{\circ}$, que la normativa reguladora del Impuesto sobre la Renta de las Personas Físicas permite la afectación parcial de elementos patrimoniales divisibles siempre que la parte afectada sea susceptible de aprovechamiento separado e independiente del resto, siendo la vivienda uno de esos supuestos en los que una parte de ella puede destinarse a la actividad profesional. Según el TEAC puede establecerse de forma objetiva la determinación de la parte del inmueble que se utiliza para la actividad profesional mediante la concreción de los metros cuadrados destinados a la misma y, partiendo de este dato, se puede hallar la porción de gastos derivados que corresponden a la parte destinada a la actividad económica. Sigue el TEAC, en la Resolución indicada, poniendo de manifiesto que "la naturaleza de los gastos de suministros impide afirmar sin mayores comprobaciones que sean imputables en la misma medida a una y a otra actividad, pues no existe una regla racional que permita discernir qué parte es utilizada para fines particulares y qué parte para el desarrollo de la actividad económica. Por ello, en ausencia de método de cálculo objetivo, entiende este TEAC que se debe imponer la regla general de admitir la deducción de aquellos gastos de suministros respecto de los que el obligado tributario pruebe la contribución a la actividad económica desarrollada, y, siguiendo la regla de correlación entre ingresos y gastos para la determinación del rendimiento neto de la actividad económica, sólo puede admitirse la deducción de aquellos gastos si su vinculación con la obtención de los ingresos resultara acreditada por el obligado tributario".

Sin embargo, en Resolución 28/18327/2015, dictada con fecha 30 de noviembre del 2018 por el TEAR de Madrid, en el F.J. 9 ${ }^{\circ}$, tras indicar el Tribunal que se había acreditado en el procedimiento instruido que la actividad se ejerce en el inmueble donde radica el domicilio particular del reclamante, con un grado de afectación del $25 \%$, en cuanto a los gastos de suministros derivados de la vivienda-, señala que, dado que los gastos de suministros que la reclamante pretende deducirse derivan de un inmueble que no se destina exclusivamente al desarrollo de la actividad, pues tal y como consta en el expediente se corresponden con gastos de suministros relativos a su vivienda habitual donde se desarrolla la actividad, según se 
alega y que no ha probado suficientemente que dichos gastos sean necesarios para la obtención de ingresos procedentes del desarrollo de la actividad profesional declarada, no proceder admitir como deducibles fiscalmente dichos gastos.

Como se puede observar hay una contradicción entre la Resolución del TEAC y la Resolución del TEAR examinadas. En la primera se admite que, cuando el contribuyente utilice unos metros de su vivienda habitual para el desarrollo de su actividad profesional, se pueda deducir la parte proporcional de gastos de suministros que sea necesaria para su actividad teniendo en cuenta la correlación de ingresos y gastos; mientras que en la segunda, habiendo quedado probado que la actividad profesional la desarrolla el contribuyente en la vivienda, sin embargo, no se admite la deducibilidad de los gastos de suministros en la proporción del 25\% porque el TEAR entiende que no queda suficientemente probado que son necesarios para la obtención de ingresos. Este tipo de contradicción, conculcan el principio de capacidad económica de los contribuyentes por cuanto, aun cuando se puede tener probado que parte de la vivienda está afectada al desarrollo de la actividad económica, sin embargo, la admisión de la deducibilidad de los gastos de suministros queda sometida al criterio discrecional de quien resuelve el asunto en cuestión.

A mayor abundamiento, resulta paradójico cuando se ha producido por la aprobación de la Ley 6/2017, de 24 de octubre, por la que se aprueban las Reformas urgentes del trabajador autónomo, una modificación del artículo 30.2 regla $5^{\mathrm{a}} \mathrm{b}$ ) de la LIRPF que indica que en los casos en que el contribuyente afecte parcialmente su vivienda habitual al desarrollo de la actividad económica, los gastos de suministros de dicha vivienda, tales como agua, gas, electricidad, telefonía e Internet, en el porcentaje resultante de aplicar el 30 por ciento a la proporción existente entre los metros cuadrados de la vivienda destinados a la actividad respecto a su superficie total, salvo que se pruebe un porcentaje superior o inferior.

Sirva el ejemplo indicado como muestra de los cambios de criterios de la Administración y que, desde luego, tienen un efecto directo en la capacidad económica efectiva de los contribuyentes.

Como se puede observar, el TEAR ha ido reduciendo las posibilidades de deducción de gastos en actividades económicas, en método de estimación directa. Esta reducción no obedece a exigencias del marco normativo. Para que un gasto sea fiscalmente deducible, la única exigencia que establece la LIRPF (de conformidad 
con el artículo 28) es que esté recogido en los registros contables y que esté afecto a la actividad económica. Y, ello es porque el rendimiento neto de las actividades económicas se determinará con arreglo a las normas del Impuesto sobre Sociedades.

En base a lo expuesto, si una parte de la vivienda habitual está afecta a la actividad profesional (despacho, estudio, etc) es razonable que la parte proporcional de los gastos de suministros correspondientes a dicha parte afecta, fueran deducibles siempre que reúnan los requisitos para la deducibilidad conforme a lo dispuesto en la LIRPF y la LIS. Y así sería conforme a la doctrina expuesta en la Resolución del TEAC 00/8141/2008, dictada el 3 de febrero del 2010. Sin embargo, de conformidad con la Resolución del TEAC 00/04454/2014, dictada con fecha 10 de septiembre del 2015 "sólo puede admitirse la deducción de aquellos gastos si su vinculación con la obtención de los ingresos resultara acreditada por el obligado tributario".

Y, si como en el caso expuesto ad exemplum (Resolución 28/18327/2015 indicada anteriormente), queda acreditado que el desarrollo de la actividad económica se hace en una parte de la vivienda que supone el 25\%; sin embargo, la Administración entiende que no es suficiente, aunque, está claro, la actividad económica en su vivienda particular, y se han declarado unos ingresos. Al respecto, ya nos hemos referido en el apartado III del presente.

Lo indicado en el párrafo anterior, resulta paradójico en sí mismo y sorprende el retorcimiento del razonamiento jurídico expuesto por el TEAR para denegar la deducibilidad del gasto a pesar de que, efectivamente, si ha tenido una vinculación directa con la obtención de ingresos, puesto que, si se desarrolla una actividad económica en la vivienda particular y se obtienen ingresos, se han tenido que producir gastos de luz, agua etc., como si de una oficina o despacho se tratara, quedando reducida la posibilidad de deducción del gasto de suministros a una cuestión probatoria, cuya carga recae en el propio contribuyente que ve, de esta forma, reducidas sus posibilidades de defensa, so pena de tener contadores diferenciados, lo que supone un coste adicional al sujeto pasivo y una exigencia excesiva, cuando se puede aplicar un porcentaje de conformidad con en el artículo 30.2 regla $5^{\mathrm{a}}$ b) de la LIRPF.

$\mathrm{Al}$ respecto de lo indicado, HERRERA MOLINA ${ }^{23}$ considera que una restricción del derecho de prueba que no permita tributar con

23 Herrera Molina, P. M.: "Capacidad económica y sistema fiscal. Análisis del ordenamiento español a la luz del Derecho alemán”, Editorial Marcial Pons. Madrid, 1998, pág. 176 
arreglo a los rendimientos reales puede infringir el derecho de tutela judicial efectiva, contemplado en el artículo 24.1 de la CE, pero lesiona también el derecho a contribuir con arreglo a la capacidad económica y añade que la restricción del derecho de prueba sólo será legítima cuando exista un fundamento constitucional para la limitación del derecho a contribuir con arreglo a la capacidad económica. Se trata, como indica HERRERA MOLINA ${ }^{24}$, de una presunción iuris et de iure puesto que constituyen instrumentos probatorios en manos de la Administración que no admite prueba en contrario.

Y, en relación con lo mencionado sobre la deducibilidad de los gastos de suministros quedando reducidos a una cuestión probatoria, supone que en muchos casos, realmente, no sólo se vulnera su derecho a contribuir conforme a su capacidad económica sino también se está vulnerando el derecho a la tutela judicial efectiva, teniendo en cuenta que, además, se está pidiendo a los contribuyentes un esfuerzo probatorio ex lege, puesto que dicha exigencia no está recogida en el artículo 30.2 regla $5^{\mathrm{a}} \mathrm{b}$ ) de la LIRPF.

Como se observa, este cambio discrecional en los razonamientos de la Administración, no obedece a exigencias normativas, visto está que el artículo 30.2, regla $5^{\mathrm{a}} \mathrm{b}$ ) fue modificado por la Ley 6/2017 mencionada anteriormente para abrir paso a la deducción de gastos de suministros en los que el contribuyente incurre en el desarrollo de su actividad económica cuando ésta se produce total o parcialmente en una parte de su vivienda habitual y particular-, sino meramente interpretativas, vulnerando el principio de capacidad económica al que se refiere el artículo 31.1 de la CE por cuanto el autónomo incurre en gastos en el ejercicio de su actividad y, sin embargo, cada vez la doctrina del TEAC, TEAR y, por ende, de la A.E.A.T. reducen la posibilidad de la deducción de los mismos.

Pero, además, vulnera el principio de seguridad jurídica y el principio de interdicción de la arbitrariedad de los poderes públicos recogidos en el artículo 9.3 de la $\mathrm{CE}$ al que nos hemos referido en el Capítulo correspondiente. A fin de evitar estos cambios de criterios doctrinales de la Administración, resultaría conveniente y deseable, en todo caso, aplicar la teoría del neto objetivo a la que hacen referencia GOROSPE OVIEDO y HERRERA MOLINA ${ }^{25}$, permitiendo que los contribuyentes en actividades económicas con

$24 \quad$ Ob.cit.pág. 177

25 Gorospe Oviedo, Juan I. y Herrera Molina, Pedro M.: "La virtualidad del principio de capacidad económica en el ordenamiento tributario español". En Albiñana, 
el método de estimación directa tributaran por la renta neta, quedando al margen aquellas cantidades correspondientes a los gastos necesarios en los que el contribuyente incurre para la obtención de sus ingresos, de modo que la carga tributaria global sea en función de la capacidad económica real de cada contribuyente. O bien, que se permitiera la deducción de los gastos necesarios derivados de la actividad económica.

No obstante, el principio de capacidad económica también resulta conculcado por las propias normas tributarias. Así, el artículo 29.1 c) de la LIRPF indica que se consideran elementos patrimoniales afectos a una actividad económica aquellos elementos patrimoniales que sean necesarios para la obtención de los respectivos rendimientos. En la actualidad, muchos de los profesionales cuyos rendimientos se determina por el método de estimación directa (en sus dos modalidades: normal o simplificada), no prestan sus servicios exclusivamente en la ciudad o zona en la que tiene su domicilio fiscal; más bien, muchos profesionales prestan sus servicios a clientes que tienen por todo el territorio español e incluso, a veces, en el extranjero. Pensemos en un abogado, ingeniero, auditor, arquitecto o asesor fiscal. Muchos de ellos prestan sus servicios a clientes que pueden estar dispersados en todo el territorio nacional o, como he indicado, incluso en el extranjero. Y, para prestar sus servicios, utilizan muchas veces sus propios vehículos.

Pues bien, el artículo 22. 4 del RIRPF, excluye la posibilidad de utilizar los bienes del inmovilizado adquiridos y utilizados para el desarrollo de la actividad económica que se destinen a uso personal del contribuyente en días y horas inhábiles a los automóviles de turismo y sus remolques, ciclomotores, motocicletas, etc. Esto pone de manifiesto una vulneración a los principios de igualdad y justicia tributaria por cuanto, si el artículo 22 exceptúa de la no deducción a aquellas profesiones que entiende que necesitan un vehículo para el desarrollo de su actividad económica, sería oportuno que admitiera la posibilidad de que, pudiendo aportar prueba de prestación de servicios a clientes afincados en otros territorios o zonas, el contribuyente interesado se dedujera los gastos derivados de la utilización del vehículo. Y, teniendo en cuenta que, la reducción del paro pasa por una política fiscal que impulse la iniciativa privada, este artículo del RIRPF debe ser revisado.

César. (Coord.) Estudios en homenaje al profesor Pérez de Ayala. Dykinson. 2007, págs. 29-56 
Asimismo, el referido artículo 22.4 del RIRPF supone una vulneración del principio de capacidad económica, por cuanto, para los gastos derivados de la utilización de los vehículos mencionados en el ejercicio de su actividad económica pueda ser considerados deducibles, es necesario que el vehículo esté totalmente afecto, no contemplándose la opción de una utilización del mismo, accesoria e irrelevante, salvo que se trate de vehículos para transporte de mercancías, transporte de viajeros. Y, entendemos que conculca el principio de capacidad económica porque el artículo 22.4 del RIRPF está obligando a que el profesional utilice un vehículo exclusivamente para su actividad económica. Además, a pesar de que así lo hiciera, tampoco le reconoce la posibilidad de deducción de los gastos derivados de la utilización del mismo salvo en casos muy tasados.

Todo lo expuesto, nos lleva a entender que, muchas veces, tanto la legislación como los propios Órganos de la Administración tributaria, excluyen la posibilidad de deducción de gastos por motivos que no son de índole legislativo, porque si no fuera así ¿Qué razón hay para denegar a unos profesionales que ejercen su actividad económica la deducción de los gastos derivados del uso de vehículo turismo? Quizás las razones puedan ser de practicabilidad administrativa o dificultad de prueba. De todas formas, sea cuáles sean los motivos que lleven a no considerar como no deducibles los gastos a los que nos venimos refiriendo, lo cierto es que están incidiendo en la capacidad económica de los contribuyentes que tienen una actividad profesional y cuyo resultado neto se calcula mediante el método de estimación directa. Y, si cercena su capacidad económica tal y como lo hace, se está vulnerando los principios constitucionales recogidos en el artículo 31.1 de la CE.

En este caso, ambas razones, vulneran el principio de capacidad económica. La primera, por cuanto supone trasladar la consecuencia de los problemas a los que se puede enfrentar la Administración, al contribuyente, de tal forma que no pudiendo comprobar la Administración la cuantía de gastos derivados de la utilización de vehículo en el desarrollo de la actividad, se prefiere negar la posibilidad de deducción. La segunda, no es tan complicado... basta con aportar las facturas emitidas a los clientes que se encuentran fuera del territorio y/o zona dónde el contribuyente tenga el domicilio fiscal, así como los gastos de manutención, para comprobar que, efectivamente, se dicho sujeto pasivo se ha tenido que trasladar para cualquier prestación de servicios. No obstante, en la dificultad de la prueba también entra un componente subjetivo. Al respecto cabe 
indicar que la Administración presupone al contribuyente como un potencial infractor.

No obstante, lo cierto es que no todos los profesionales pueden permitirse el lujo de tener un vehículo afecto, exclusivamente, a su actividad económica. Y, es en este punto, en donde queda vulnerado el principio de capacidad económica puesto que, hoy en día, el automóvil, constituye un elemento patrimonial esencial para la obtención de ingresos y, por ende, para la obtención de rendimiento de la actividad. Exigir una afectación exclusiva de un elemento patrimonial incide en la capacidad económica de quien realiza una actividad económica cuando ésta no consiste en transporte de mercancía o transporte de viajeros.

\section{VERTIENTES DEL PRINCIPIO DE CAPACIDAD ECONÓMICA}

De conformidad con RODRÍGUEZ BEREIJO ${ }^{26}$ la Constitución formula del modo más fuerte y estricto una exigencia (mandato al legislador) respecto de su libertad de configuración en materia tributaria. La capacidad económica de cada uno es el fundamento de legitimidad, la medida y el límite máximo de su justa contribución, mediante el pago de tributos, al sostenimiento de los gastos públicos.

Para RODRÍGUEZ BEREIJO, la capacidad económica es, en materia tributaria, medida de igualdad así como el fundamento de la unidad y racionalidad del sistema tributario; unidad que es imprescindible para que exista igualdad tributaria (TIPKE) y que obliga a los poderes públicos - como ha indicado el Tribunal Constitucional en la STC 27/1981, ${ }^{\circ} \mathrm{F} . \mathrm{J}^{\circ} 4^{\circ}$ y a la que nos hemos referido anteriormente-, a buscar la riqueza allí dónde la riqueza se encuentra o a exigir esa contribución a todos los contribuyentes cuya situación ponga de manifiesto una capacidad económica susceptible de ser sometida a tributación, tal y como se indica en la STC 10/2005, F.J.6 . Esto conecta el principio de capacidad económica con el principio de generalidad y el principio de igualdad de la imposición, puesto que, en palabras de RODRÍGUEZ BEREIJO27, "un sistema tributario sólo podrá ser justo y el reparto de la carga fiscal equitativo si todos los que exteriorizan manifestaciones de capacidad económica contribuyen

26 Rodríguez Bereijo, A.: "Breve reflexión sobre los principios constitucionales de justicia tributaria”, Revista Jurídica Universidad Autónoma de Madrid, Agosto, 2016, págs. 236-241.

27 Ob.cit. págs. 236-241. 
de acuerdo con ella al sostenimiento del gasto público y lo hacen con igualdad, sin diferenciaciones de trato o discriminaciones que carezcan de justificación objetiva y razonable o sean desproporcionadas", circunstancia que en el supuesto expuesto del artículo 22 RIRPF no se cumple tal y como hemos puesto de manifiesto anteriormente.

La STC 27/1981, de 21 de julio de 1981, en el F.J. $4^{\circ}$ indica que, cuando el artículo 31.1. de la Constitución obliga a todos a contribuir al sostenimiento de los gastos públicos "ciñe esta obligación en unas fronteras precisas: la de la capacidad económica de cada uno y la del establecimiento, conservación y mejora de un sistema tributario justo e inspirado en los principios de igualdad y progresividad". Para el TC capacidad económica, referida a la contribución de los gastos públicos significa la incorporación de la exigencia lógica de buscar la riqueza dónde ésta se encuentre, pese a que esta lógica no asegure un sistema tributario justo, que se inspire en los principios de igualdad y progresividad, aunque el propio TC entiende que definir lo que para definir lo que entiende justo a efectos tributarios hay que tener en cuenta que el legislador vincula el principio de justicia tributaria al de progresividad.

Hemos de indicar al respecto, que no podemos estar totalmente de acuerdo con el criterio expuesto por el TC, puesto que el principio de justicia tributaria debe estar también vinculado al principio de justicia e igualdad tributaria (como hemos indicado anteriormente al referirnos a la problemática suscitada por el artículo 22 RIRPF) a fin de no crear diferencias entre los contribuyentes en situaciones en los que no procede realizarlas.

En relación con lo expuesto, hay que indicar que es lógico que se exija la contribución al sostenimiento del gasto público a todos los contribuyentes cuya situación ponga de manifiesto una capacidad económica real. Muy al contrario de lo que entiende la jurisprudencia del TC, consideramos que, tal y como entiende DE VICENTE DE LA CASA ${ }^{28}$, la capacidad económica debe ser real, no potencial o ficticia, ya que la capacidad económica ficticia, al ser irreal, no puede ser un fundamento para la imposición de una tributación puesto que no refleja una capacidad económica real. Y, la capacidad económica potencial como puede hacerse real o no, si queda gravada y no se hace real estamos ante una capacidad económica ficticia y, por

28 De Vicente De la Casa, F.: "Los principios de capacidad económica y no confiscatoriedad como límite a la concurrencia de tributos". Crónica Tributaria ${ }^{\circ}$ 144/2012. págs.149-175

(C) UNED. Revista de Derecho UNED, núm. 28, 2021 
ende, irreal. Por lo que entendemos que un sistema tributario justo es aquel que grava, exclusivamente, la capacidad económica real.

El TC indica que una frontera precisa a la obligación que establece el artículo 31.1 de la CE de contribuir al sostenimiento del gasto público es la capacidad económica de cada uno. En este punto, es necesario indicar que, para que esto sea real y no conculque el principio de capacidad, en el caso de los profesionales que calculan el rendimiento neto de su actividad económica mediante el método de estimación directa en sus dos modalidades - normal y simplificada-, el rendimiento gravado en renta debería de calcularse mediante la aplicación de la teoría del neto objetivo, por cuanto, en la actualidad, están viendo reducido el derecho de deducción de gastos necesarios para la obtención de los rendimientos netos $\mathrm{y}$, como hemos puesto de manifiesto en el enunciado anterior, no sólo por los Órganos de la Administración Tributaria, sino por la propia normativa tributaria.

Además, hay que tener en cuenta que, a los contribuyentes en actividades económicas, no se les garantiza unos ingresos a priori, ni el poder contar con un número de clientes que les aporten un mínimo de ingresos mensuales y anuales. Es por ello que, a fin de poder obtener unos resultados positivos que puedan ser gravados en IRPF, deben de realizar unos gastos necesarios para dar el servicio para el que ha sido contratado. Este es un punto de extremada importancia. El legislador olvida que el contribuyente en actividades económicas, no tiene unos ingresos garantizados y que, generalmente, los gastos necesarios para el desarrollo de la actividad económica van por delante de la obtención de ingresos.

Tal y como indica RODRÍGUEZ BEREIJO ${ }^{29}$, el principio de capacidad económica, es fundamento del sistema tributario español (aunque no exclusivamente) y límite de los poderes públicos.

Efectivamente, el artículo 31.1 de la CE indica como principios inspiradores del sistema tributario español la capacidad económica junto con los principios de justicia (entendida como justicia tributaria, no como el principio general de justicia), el principio de progresividad, el principio de generalidad, el principio de igualdad tributaria y el principio de no confiscatoriedad. Pero, como se verá, estos principios no son los únicos. El hecho de que la CE recoja el principio de capacidad económica dentro de su artículo, supone que queda incorporado al marco constitucional en su conjunto. Por ello

29 Ob. cit. págs. 236-241. 
debe entenderse también vinculado al principio de legalidad y al principio de interdicción del arbitrio de los poderes públicos, recogidos en el artículo 9.3 de la $\mathrm{CE}$, aspecto a los que nos referiremos más adelante.

Para MARÍN-BARNUEVO FABO ${ }^{30}$, el principio de capacidad económica tiene una doble vertiente que determina, a su vez, un doble criterio de control constitucional. Por un lado, constituye el fundamento de la imposición de tal modo que solo pueden establecerse tributos cuyo hecho imponible sea revelador de capacidad económica, actuando como medida límite del legislador, (exigencia que llevó a declarar la inconstitucionalidad de la regulación del Impuesto sobre Actividades Económicas que no preveía la minoración de cuotas en caso de cese de actividad, porque gravaba, tal y como se indicó en STC 193/2004, ${ }^{\circ} \mathrm{F} . \mathrm{J}^{\circ}$. $7^{\circ}$, "situaciones de hecho inexpresivas de capacidad económica lo que contradice frontalmente el principio de capacidad económica."). Por otro lado, el principio de capacidad económica debe manifestarse y respetarse en los elementos de cuantificación del tributo, de tal forma que cada contribuyente soporte la tributación efectiva correspondiente a su capacidad económica real, actuando como medida de imposición.

Poniendo en relación la obligación indicada por el TC - en STC 27/1981, de 20 de julio, F.J.4º-, de buscar la riqueza allá dónde se encuentra con lo expuesto por MARÍN-BARNUEVO, de respetar el principio de capacidad económica de tal forma que cada contribuyente soporte la tributación que corresponda a su capacidad económica real, podemos indicar que, el límite de buscar la riqueza allá dónde se encuentre, tiene como límite la capacidad económica real que puede soportar cada contribuyente.

Siguiendo la línea argumentativa anterior, cabe indicar que el TC ha recogido este sentido en numerosas sentencias. Así en STC 126/2019, de 31 de octubre, F.J.3º, (en relación con las plusvalías municipales), indica que basta para que la capacidad económica exista como riqueza o renta real o potencial en la generalidad de los supuestos contemplados por el legislador al crear un impuesto, para que se entienda que el principio de capacidad económica ha quedado a salvo, no siendo admisible que el legislador pueda establecer tributos en aquellos supuestos en los que los actos o hechos tomados

30 Marín-Barnuevo Fabo, D.: "La doble vertiente del principio de capacidad económica en la jurisprudencia constitucional". Revista El Notario del Siglo XXI, N ${ }^{\circ} 82$ https://www.elnotario.es/hemeroteca/revista-82/9027-la-doble-vertiente-del-principio-de-capacidad-economica-en-la-jurisprudencia-constitucional. 
en consideración para el establecimiento de los mismos no sean un exponente de una riqueza real o potencial $\mathrm{y}$, mucho menos, cuando la capacidad económica gravada sea virtual o ficticia. El TC distingue entre gravar una renta potencial y otra muy distinta es someter a tributación una renta irreal.

No obstante, no parece que una renta potencial pueda ser motivo suficiente para considerar que queda salvado el cumplimiento del principio de capacidad económica en el establecimiento de un tributo. Tal y como hemos expuesto anteriormente, hay que traer a colación lo expuesto por DE VICENTE DE LA CASA ${ }^{31}$, al indicar que una renta potencial es ficticia porque no es más que una posibilidad de que la renta llegue a producirse. Si al final no se produce, nos encontraremos ante una renta inexistente o ficticia, conculcándose el principio de capacidad económica. En este mismo sentido se expresa ÁLVAREZ ARROYO ${ }^{32}$. Solamente se puede justificar el uso de la renta potencial para establecer un tributo y es que se establezca un mecanismo de devolución o compensación tal y como indica MOSCHETTI $^{33} \mathrm{y}$, esto es, según el autor, necesario porque el defecto no está en el hecho de la anticipación, sino en la elección del hecho imponible, pues una potencialidad es, por definición, lo contrario a capacidad efectiva y, por tanto, cierta.

De acuerdo con lo expuesto, queda puesto de manifiesto la necesidad de contribuir al gasto público de acuerdo con la capacidad económica de cada uno, pero que dicha capacidad debe ser real, pero nunca ficticia. No compartimos tampoco la idea de renta potencial como fundamento para el establecimiento de los tributos por cuanto, como se ha indicado anteriormente, la renta potencial puede no llevarse a efecto y, en ese caso, también sería ficticia, a no ser que, el propio tributo contenga un mecanismo de devolución o compensación, lo cual supone abocar al contribuyente a iniciar un procedimiento de solicitud de ingresos indebidos largo y farragoso para que el principio de capacidad económica no se vea conculcado.

31 De Vicente De la Casa, F.: "Los principios de capacidad económica y no confiscatoriedad como límite a la concurrencia de tributos". Crónica Tributaria ${ }^{\circ}$ 144/2012., págs. 149-175

32 Álvarez Arroyo, F.: "El impuesto Municipal sobre Construcciones, Instalaciones y Obras". Aranzadi. Pamplona. 1996, pág.27 quien considera que la jurisprudencia del TC ha vaciado de contenido dicho principio, llevándolo al absurdo de que a una persona en situación de desempleo también puede se le puede asignar una renta presunta.

33 Moschetti F.: "El principio de capacidad contributiva". Estudios de Hacienda Pública. Madrid. 1980, págs. 384-385. 
Para GOROSPE OVIEDO y HERRERA MOLINA ${ }^{34}$ hay que diferenciar dos tesis:

- la tesis de la interdicción de la arbitrariedad que se fundamenta en la concepción de la capacidad económica como mera riqueza potencial. En este caso, de conformidad con lo indicado por el Tribunal Constitucional, el principio de capacidad económica opera como un límite al poder legislativo en materia tributaria (SSTC 221/1992, F.J.4; 214/1994, F.J. $5^{\circ}$ y 194/2000, F.J. $8^{\circ}$ ). Tal y como dice el Tribunal la libertad del Legislador deberá de respetar los límites que derivan de este principio, ya que quebraría en aquellos supuestos en los que la capacidad económica gravada no sea ya potencial sino inexistente o ficticia.

En cuanto a los límites a la libertad del legislador, los autores mencionados hacen referencia a la STC 134/1996. F.J.8 ${ }^{\circ}$, en la que el Tribunal indica que, en el legítimo ejercicio de su libertad de opción política, lo que no puede hacer es contravenir los principios establecidos en el art. $14 \mathrm{CE}$ y en el art. 31.1. CE. Este principio, sin embargo, tal y como indica el Tribunal en STC 46/2000, F.J.7 ${ }^{\circ}$, no exige que el legislador tenga que dar un trato igualitario. Tal y como señalan GOROSPE OVIEDO y HERRERA MOLINA, esta libertad del legislador en ocasiones llega a vulnerar la Constitución, como sucede con la prohibición de que los rendimientos del capital inmobiliario sean negativos al no poder exceder el importe de gastos deducibles de la cuantía de los rendimientos netos, de conformidad con el artículo 13 del RIRPF.

- la tesis del derecho a contribuir con arreglo a la capacidad económica como medida general de igualdad. Al respecto, GOROSPE OVIEDO y HERRERA MOLINA, ponen de manifiesto los diferentes criterios seguidos por el Tribunal Constitucional. Así, en algunas sentencias del Tribunal se refiere a la capacidad económica como medida de la igualdad y, por tanto, el legislador ha de ordenar la tributación en atención a la capacidad económica que muestren los ciudadanos (ad exemplum, SSTC 209/1998, F.J. 6º 45/1989, F.J.4 ${ }^{\circ} .2$ y $7^{\circ} .7 ;$ 46/2000, F.J. $7^{\circ}$ y $8^{\circ}$ ). En otras sentencias, el Tribunal ha tratado el principio

34 Gorospe Oviedo, Juan I. y Herrera Molina, Pedro M.: "La virtualidad del principio de capacidad económica en el ordenamiento tributario español". En Albiñana, César. (Coord.) Estudios en homenaje al profesor Pérez de Ayala. Dykinson. 2007, págs. 29-56 
de igualdad en supuestos que podrían vulnerar la Constitución desde la perspectiva de la capacidad económica como medida de igualdad, puesto que da el mismo trato a situaciones desiguales (verbigracia STC $1 / 2000$, F.J. $3^{\circ} ; 47 / 2001$, F.J. $7^{\circ}$, $212 / 2001$ y $21 / 2002$.

El TC indica que el legislador debe ordenar la tributación en atención a la capacidad económica del contribuyente. Obviamente, en el caso de las actividades económicas (cuyo rendimiento neto se calcule mediante el método de estimación directa normal o simplificada), no pueden incluirse dentro del mencionado rendimiento los gastos necesarios para la obtención de dicho resultado.

En este aspecto, tanto el legislador como la doctrina del TC no han tenido en cuenta que para la obtención de ingresos y, por ende, de rendimientos netos, hay que realizar unos gastos. Dichos gastos, para el sujeto pasivo que tiene una actividad económica son gastos esenciales sin los que no podría desarrollar su actividad y, por ende, obtener ingresos.

Por ello la capacidad económica no puede ser la global sino la diferencia entre los ingresos obtenidos y los gastos necesarios; porque de otra forma, tal y como ocurre en la normativa vigente, se está presumiendo a los contribuyentes, que desarrollan una actividad económica, una capacidad económica irreal, ficticia.

Ni siquiera, considero la posibilidad de capacidad económica potencial, puesto que una parte de sus ingresos van destinados a cubrir los gastos necesarios para el desarrollo de su actividad, quebrando, de esta forma el mandato contemplado en el artículo 28 de la LIRPF, por cuanto, aunque el mencionado precepto remite a las reglas contempladas en la LIS para el cálculo del rendimiento neto, sin embargo, el legislador y la doctrina del TC no tienen en cuenta la capacidad económica real que serían el rendimiento neto objetivo obtenido descontado los gastos necesarios.

En relación con lo mencionado, debemos indicar que, los ingresos y gastos que se deben incorporar en los registros contables deben ser los que realmente se tienen, a fin de que la contabilidad sea la imagen fiel, como se exige en los principios contables. Si hablamos de una capacidad económica potencial, no nos referimos a ingresos y gastos reales, sino presumibles y, salvo que efectuemos los oportunos aprovisionamientos que pudiéramos realizar por gastos futuros conocidos o por insolvencias de clientes, el resto no se puede aventurar y, por ende, no debe recogerse en contabilidad. 
GOROSPE OVIEDO y HERRERA MOLINA señalan, además, que, en otros pronunciamientos, el Tribunal efectúa una ponderación de los bienes jurídicos entre las exigencias de la practicabilidad administrativa (o lucha contra el fraude) y el principio de capacidad económica, lo que supone un control a la interdicción de la arbitrariedad y supone implícitamente la existencia del derecho a contribuir con arreglo a la propia capacidad económica cono especificación del derecho a la igualdad (SSTC 45/1989; 146/1994; 214/1994; $194 / 2000 \ldots$... En este punto hay que indicar que puede que de forma abstracta suponga un control de la interdicción de la arbitrariedad. En la práctica, tal y como hemos indicado al hablar de la deducción de gastos de suministros correspondientes al porcentaje de uso de la parte de la vivienda particular afecta a la actividad económica, no se logra dicha interdicción. Son los propios órganos de la Administración los que consideran o no la posibilidad de que el contribuyente se deduzca los gastos de suministros indicados, quedando a expensas del criterio aplicable en ese momento por la Administración y viendo su principio de capacidad económica conculcado, a expensas de un control judicial posterior que supone un coste importante para el contribuyente si quiere acreditar el gasto que ha mermado su capacidad económica.

De todas las líneas doctrinales expuestas, parece ponerse de manifiesto que la capacidad económica, por un lado, sirve como límite de la arbitrariedad de los poderes públicos, por otro lado, tiene la vertiente de medida de igualdad en cuanto al derecho a contribuir conforme a la capacidad económica de cada uno.

No obstante, como se ha puesto de manifiesto en líneas superiores, no siempre el principio de capacidad económica opera como límite de la arbitrariedad de los poderes públicos, por cuanto el conocimiento previo, en vía administrativa, de los recursos compete a la A.E.A.T., TEAR y TEAC y, en este sentido, el sujeto pasivo se encuentra, en la mayoría de las situaciones, en indefensión por las variaciones de criterios seguidos. Variaciones que, en muchas ocasiones, afectan a la capacidad económica de los contribuyentes, que se ven obligados a buscar en los tribunales la tutela judicial de sus derechos e intereses.

Y como medida de igualdad en cuanto al derecho a contribuir conforme a la capacidad económica de cada uno, podríamos señalar que, en muchas ocasiones no se obtiene. Es sabido que la diferencia de normativa (procedente de la delegación de facultades a las CCAA) ha supuesto que muchas personas, se hayan visto obligadas a renunciar a 
la herencia (derecho que se encuentra recogido en art. 33.1 de la CE) por los tipos impositivos elevados que en algunas CCAA se han establecido. Por lo que, en este aspecto, aun cuando dentro de cada CCAA el trato es igualitario y los tipos se establecen para todos los habitantes de la misma, sin embargo, en estas ocasiones, la igualdad quiebra el principio de capacidad económica y vulnera el derecho a la herencia (recogido en el artículo 33.1 de la CE).

\section{TRATAMIENTO DOCTRINAL DEL PRINCIPIO DE CAPACIDAD ECONÓMICA}

El tratamiento de capacidad económica no es unánime en la doctrina. Así, CALDERÓN CORREDOR ${ }^{35}$ pone de relieve, entre estas corrientes doctrinales a HERRERA MOLINA ${ }^{36}$. HERRERA MOLINA preconiza que la medida general de contribución a los gastos públicos viene dada por la capacidad económica o riqueza disponible, sin embargo, la aplicación del principio de capacidad económica no prima sobre el interés general, por lo que admite que para conseguir fines extrafiscales con carácter excepcional el legislador se aparte del mismo. Según HERRERA MOLINA, esto debe estar acompañado de ciertas cautelas que aseguren la menor distorsión posible del principio de capacidad económica

El propio TC hace un uso confuso y variable del principio de capacidad económica para hacerlo compatible con fines extrafiscales tal y como indican GOROSPE OVIEDO y HERRERA MOLINA ${ }^{37}$.

En este sentido también se manifiesta YEBRA MANTUL-ORTEGA $^{38}$, al indicar, tal y como expone CALDERON CORREDOR ${ }^{39}$, que el TC no termina de precisar el significado del principio de capacidad económica y después de afirmar que no es el único criterio

35 Calderón Corredor, Z.: "Principios impositivos de justicia y eficiencia: fundamentos, conflicto y proyección. Un enfoque multidisciplinar". Editorial Dykinson. Colección Fiscalidad. Madrid, 2017. pág. 110.

36 Herrera Molina, P.: "Metodología del Derecho Financiero y Tributario". Documentos, $n^{\circ}$ 26/03. Instituto de Estudios Fiscales. 2003, págs. 270-277.

37 Gorospe Oviedo, Juan I. y Herrera Molina, Pedro M.: "La virtualidad del principio de capacidad económica en el ordenamiento tributario español". En Albiñana, César. (Coord.) Estudios en homenaje al profesor Pérez de Ayala. Dykinson. 2007, págs.29-56

38 Yebra Mantul-Ortega, P.: “Artículo 31.3 de la Constitución”. Op. Cit., pág. 502.

39 Calderón Corredor, Z.: "Principios impositivos de justicia y eficiencia: fundamentos, conflicto y proyección. Un enfoque multidisciplinar". Editorial Dykinson. Colección Fiscalidad. Madrid, 2017. pág. 113. 
de justicia, hace referencia a la riqueza real y a la potencial, aunque advierte que no se puede gravar rentas inexistentes (ad exemplum STC 126/2019, F.J.3; SSTC 26/2017, F.J 3; 37/2017, F.J.3; 59/2017, F.J. $3^{\circ}$ y $72 / 2017$, F.J. $3^{\circ}$, a las que nos hemos referido ut supra), además de utilizar conceptos jurídicos indeterminados.

SAINZ DE BUJANDA ${ }^{40}$ indica que “Tendrán, pues, fundamento jurídico constitucional aquellos hechos imponibles que directa o indirectamente configuren manifestaciones de riqueza o de la renta... esas manifestaciones de la capacidad económica que se pretenden someter a imposición son el objeto de los distintos tributos... Si el hecho imponible definido en la ley tributaria entra en colisión con el antedicho criterio, la obligación tributaria no será válida mas no porque a ella le falte causa, sino porque el hecho que pretende generar el vínculo de obligación carece en sí mismo de fundamento constitucional". Y, evidentemente, en la normativa vigente del IRPF (tanto Ley como Reglamento) en relación a los rendimientos de actividades económicas en método de estimación directa, el hecho imponible entra en colisión con el criterio indicado pues el rendimiento neto sometido a tributación no es real dado que no tiene en cuenta un rendimiento neto objetivo, y, al no ser real, se está presumiendo a los contribuyentes de las actividades económicas indicadas, una riqueza o renta superior a la que en realidad obtienen.

Para GOROSPE OVIEDO y HERRERA MOLINA ${ }^{41}$ el criterio de tributación con arreglo a la capacidad económica constituye el núcleo central de los principios contenidos en el artículo 31.1. de la CE; por un lado, supone el criterio general de la igualdad en materia tributaria y, por otra parte, la progresividad y la no confiscación son principios corolarios del principio de capacidad económica. El principio de progresividad es conseguir la igualdad material a través de la redistribución de renta. El principio de no confiscatoriedad supone un límite a la progresividad, puesto que impide agotar la capacidad económica, y, además, confirma, dentro del ámbito tributario, el derecho a la propiedad privada recogido en el artículo 33.1 de la CE. La justicia tributaria se plasma en el cumplimiento del principio de capacidad económica, aunque puedan darse excepciones basadas

40 Sainz de Bujanda, F.: "Análisis jurídico del hecho imponible". Revista de Derecho Financiero y Hacienda Pública, n 61, 1965, págs. 153 a 155 y 160, así como en "Hacienda y Derecho" Vol. IV., Instituto de Estudios Fiscales. Madrid, 1966 pág. 551.

${ }_{41}$ Gorospe Oviedo, Juan I. y Herrera Molina, Pedro M.: "La virtualidad del principio de capacidad económica en el ordenamiento tributario español”. En Albiñana, César. (Coord.) Estudios en homenaje al profesor Pérez de Ayala. Dykinson. 2007, págs.29-56 
en otros principios constitucionales relativos a política sanitaria, social, laboral, asistencial, medioambiental, cultural, etc... En relación a lo expuesto sobre las exenciones, los autores indicados hacen referencia a la STC 96/2002, de 25 de febrero, que indica que "la exención o la bonificación, como quiebra del principio de generalidad que rige en la materia tributaria (art.31.1 CE), en cuanto que neutraliza la obligación tributaria derivada de la realización de un hecho generador de capacidad económica, sólo será constitucionalmente válida cuando responda a fines de interés general que la justifiquen."

Consideramos que, dado que la $\mathrm{CE}$ recoge el principio de capacidad económica como la base por la cual los contribuyentes debemos contribuir al sostenimiento del gasto público y, teniendo en cuenta que en el IRPF se grava la renta obtenida por rendimientos de trabajo, ahorro, actividades económicas, ganancias y pérdidas patrimoniales, sería loable que el legislador, a fin de poder proteger la capacidad económica de los contribuyentes, perfilase el rendimiento neto de las actividades económicas. Y todo ello porque la regulación del LIRPF y del RIRPF no corresponde a la realidad y de ello se deriva que los contribuyentes que desempeñen una actividad económica y, cuyo rendimiento se calcule por el método de estimación directa, estén soportando una tributación que no corresponde al rendimiento neto real obtenido de su actividad económica sino, en la mayoría de las ocasiones, por encima de lo que les debiera corresponder.

\section{CONCLUSIONES}

En base a todo lo expuesto, consideramos que el principio de capacidad económica, entendida como la posibilidad real de una persona para hacer frente a las obligaciones tributarias, debe referirse a una capacidad económica real y no potencial o ficticia, por cuanto la capacidad económica potencial es una posibilidad de que la renta llegue a producirse. Si no se produce finalmente, estaríamos ante una renta inexistente, irreal. Esto vulnera el principio de capacidad económica. No obstante, podría entenderse un gravamen de una renta potencial siempre y cuando el propio tributo contara con un mecanismo para devolución de ingresos indebidos provocados por el hecho de que no se hubiera producido la esperada renta gravada. Esto, obviamente, supone una exigencia para el legislador de incluir mecanismos de devolución en cada uno de los tributos y la necesidad de establecer los supuestos de hecho en los que debería efectuarse la consecuente devolución. 
A fin de conseguir que la renta gravada sea la renta real, la normativa de IRPF debería incluir el principio de neto objetivo para la cuantificación del resultado las actividades económicas que se grava, de tal forma que sólo soportara el gravamen correspondiente, el resultado neto y no la totalidad de ingresos y gastos.

Pero, obviamente, esta solución no es solo la única. A fin de actualizar los mínimos personales y familiares recogidos en el IRPF, debería aplicarse el principio de neto subjetivo, toda vez que los recogidos en el IRPF no recogen los mínimos personales y familiares conformes a la actualidad y queda muy desfasada.

Se pone pues, de manifiesto, la necesidad de efectuar una revisión y/o actualización de la normativa vigente de IRPF. No sólo en lo expuesto en relación con los rendimientos de actividades económicas o mínimos personales y familiares; sino también en relación con los gastos derivados del uso de vehículos por contribuyentes en actividades económicas diferentes a los que el RIRPF permite la deducción del referido gasto. Y ello, a fin de evitar no sólo la posible vulneración del principio de capacidad económica, sino la vulneración del principio de igualdad y justicia tributaria.

Además, se pone de manifiesto la necesidad de obtener de los órganos de la Administración, TEA y órganos jurisdiccionales criterios uniformes en relación con los siguientes aspectos:

- unidad de criterio de concepto de principio de capacidad económica,

— unidad de criterio sobre la capacidad económica que debe ser objeto de gravamen.

Pero, sobre todo, se hace prioritaria la necesidad de una doctrina jurisprudencial uniforme en relación con la deducibilidad de gastos en actividades económicas para evitar que la misma quede reducida a una cuestión de prueba y de practicabilidad de la misma.

Todo lo indicado adquiere importancia puesto que redunda ya no sólo en la capacidad económica del contribuyente lo que, en los tiempos que corren, es primordial, sino, además de los principios expuestos, también en el principio de seguridad jurídica y, sobre todo, al principio de confianza legítima, principio que deberían los órganos jurisdiccionales a incluirlo en su doctrina y al que dedicaremos, igualmente, el epígrafe correspondiente. 